\title{
DESAFIOS DO ENSINO E DA PESQUISA EM DESIGN NA PÓS-GRADUAÇÃO
}

\author{
Profa. Dra. Maria Cecília Loschiavo dos Santos \\ Prof. Dr. Rafael Antonio Cunha Perrone \\ Professores do Departamento de Projeto/Graduação e orientadores no Curso de Pós-Graduação da \\ FAUUSP.
}

Há algum tempo era necessária uma revisão crítica das atividades de ensino e pesquisa do desenho industrial e da programação visual no Brasil, no âmbito da pós-graduação. A institucionalização do ensino superior em design, no Brasil, remonta ao início dos anos 60, por meio das experiências pioneiras, da ESDI-RJ e da FAUUSP. Nos últimos anos o país vem estruturando seus primeiros programas de pós-graduação, o primeiro dos quais foi implantado na Pontifícia Universidade Católica do Rio de Janeiro, com muito êxito.

Decorridos cerca de 40 anos dessas experiências pioneiras, a FAUUSP, respondendo a uma demanda expressiva de estudantes de pós-graduação, desejosos de realizar pesquisas na área do design, passou a discutir a montagem de uma área de concentração em design e arquitetura, bem como o conjunto de atividades envolvidas: a concepção dos conteúdos disciplinares; a delimitação do campo e dos objetos a serem estudados, a seleção dos métodos e técnicas a serem empregadas e, por fim e acima de tudo, a definição dos objetivos a serem alcançados.

Com a intenção de fundar posições e entrever possibilidades para construção dessas atividades e objetivos, um grupo de professores das áreas de Programação Visual (PV) e Desenho Industrial (DI) propôs um seminário internacional com o tema: "Perspectivas do Ensino de Design na Pós-Graduação". Após intensa mobilização interna, o seminário foi realizado na FAU-Maranhão, no período de 25 a 28 de setembro de 2001.

\section{OBJETIVOS DO SEMINÁRIO}

O objetivo central do seminário foi o de contribuir para formular as bases da área de "design e arquitetura", na constituição do futuro conjunto de áreas de concentração do curso de pós-graduação.

Como objetivos interligados o seminário visou: 1) analisar criticamente as principais experiências de ensino e design implantadas no país; 2) conhecer e debater algumas experiências estrangeiras; 3) sistematizar parâmetros de ensino e pesquisa em design, com base nas diferentes vocações e especificidades contidas em sua formação disciplinar; 4) buscar equacionar as relações comunicação 
visual, desenho industrial e arquitetura para a definição da área "design e arquitetura".

\section{ORGANIZAÇÃO DO SEMINÁRIO}

A abrangência do design e sua relação com a arquitetura e o urbanismo foram preocupações constantes durante todo o evento. De um modo mais simplificado, a configuração do estudo do design, em uma abordagem interdisciplinar com a arquitetura, esteve presente em todas as atividades realizadas durante o seminário.

O seminário foi organizado com as seguintes formas de participação:

\section{Palestras}

Professores convidados - Experiências em pesquisa e ensino.

\section{Mesa-redonda}

Pesquisadores convidados - Experiências brasileiras em pós-graduação.

\section{Depoimentos}

Professores convidados - Registro das contribuições para o ensino do design.

\section{Mesas temáticas}

Trabalhos enviados - Registro de pesquisas.

Esse formato foi estabelecido para a adequação aos objetivos do seminário bem como para discutir a produção científica de nossos alunos da pósgraduação.

Participantes de várias universidades brasileiras e internacionais trouxeram suas contribuições, dentro da amplitude necessária para o estabelecimento de um debate e balizamento do curso futuro. As palestras não apenas trouxeram o relato das experiências dos convidados, mas também compartilharam de um foco comum quanto aos pressupostos básicos para o estabelecimento e a consolidação de uma cultura de design na pós-graduação.

Os palestrantes convidados e seus respectivos temas foram os professores: Anna Calvera (Universidad de Barcelona, Espanha) - "Teoría / Ensino y Pesquisa del Design"; David Durling (Staffordshire University, UK) - "Design Research"; Guilherme Cunha Lima (ESDI/UERJ, Rio de Janeiro) - "O Ensino e a Pesquisa em Design na ESDI"; Maria Cecília Loschiavo dos Santos (FAUUSP, São Paulo) - "A Formação do Designer: Aspectos da Didática e da Pesquisa".

As palestras tiveram, como foco, a transmissão das experiências realizadas em cada instituição ou país. Essas experiências foram relacionadas, pelos palestrantes, com as atividades de ensino e pesquisa na definição dos estudos e cursos de pós-graduação.

O professor David Durling enfocou o caráter e a natureza das investigações em si mesmas, reiterando as especificidades da pesquisa em design, distinguindo-o do estrito ensino para a formação profissional. 
A professora Anna Calvera nos apresentou a organização de um território interrogativo. Aproveitou a oportunidade para esclarecer os conceitos "Research into design" , "Research through design" e "Design as research". Por meio desses breves conceitos indagou sobre "o que mudou na sociedade e na cultura contemporâneas para que o design como tal, e a pesquisa que pertence ao desenvolvimento de um projeto, já não sejam suficientes para a inovação e que se sinta necessidade de pesquisar de outra maneira?"1.

O professor Guilherme Cunha Lima apresentou um relato das experiências pioneiras do ensino do design na ESDI que definiram, em parte, o modo como a atividade do design é compreendida atualmente no Brasil. Reforçou que os cursos de pós-graduação são necessários para a definição de uma teoria do design própria do Brasil.

A professora Maria Cecília Loschiavo formulou um conjunto de condições e elementos capazes de estabelecer vínculos entre a pesquisa e o ensino na formação do designer, discutindo, entre outras, as seguintes questões: "como propiciar uma educação criativa em design na pós-graduação? Como propiciar uma educação crítica em temas contemporâneos em design? Em quais bases é realizada a prática do design e como o produto do design afeta a sociedade?".

(1) Trecho da apresentação (texto) da professora Anna Calvera (tradução dos autores).

\section{O DEBATE GERAL - MESA-REDONDA}

Para o primeiro dia de debates foi configurada uma mesa-redonda que procurou estabelecer um confronto entre os conteúdos dos principais cursos de pós-graduação em design em atividade no Brasil.

A mesa foi denominada "A experiência brasileira do ensino de design na pós-graduação: Conexões e diversidades".

Participaram dessa mesa os pesquisadores: professores Itiro Ida (UNB), Wilson Kindlein (UFRGS), Jairo Drumond (UEMG) e a professora Rita Couto (PUCRJ), sendo a mesa coordenada pelo professor Guilherme Cunha Lima (ESDI-RJ).

Foram relatados os trabalhos de pesquisa e o andamento de cada um dos núcleos de estudo representados. Estes relatos revelaram a gama de linhas de pesquisa abrangidas pelo design.

Além da amplitude de possibilidades, delineou-se, ainda que de modo impreciso, a conclusão que os melhores resultados de pesquisa estão ligados a uma boa configuração das áreas e linhas de pesquisas a serem realizadas.

Observou-se que por serem ainda recentes, muitas experiências carecem de uma maior continuidade e longevidade para uma apreciação mais concreta de seus resultados.

Durante a sessão houve participação da arquiteta Ivone Salgado, representando a Fapesp, que expôs de maneira sucinta algumas das expectativas dos órgãos financiadores da pesquisa. 
(2) Trecho da apresentação (texto) da professora Lucrécia D'Alessio Ferrara.

(3) Trecho da apresentação (texto) da professora Lucrécia D'Alessio Ferrara.

\section{DEPOIMENTOS}

Para a sessão de depoimentos do seminário foram convidados professores e pesquisadores que participaram da elaboração dos primeiros cursos ou disciplinas de design, ou que tenham contribuído significativamente para a fundação e transmissão de conhecimentos nessa área.

As experiências externas foram relatadas pela professora Anamaria de Moraes (PUC-RJ) e pelo professor José Plácido da Silva (Unesp-Bauru).

A professora Anamaria de Moraes descreveu sua longa trajetória de pesquisa e o desenvolvimento de um conjunto de conhecimentos produzidos na área de ergonomia.

O professor Plácido discorreu sobre o processo de elaboração da proposta do curso de pós-graduação da Unesp de Bauru.

Os depoimentos internos foram dados por vários professores da FAU. 0 professor Júlio Katinsky nos contou, entre outras coisas, sobre as origens da formação do curso de Desenho Industrial na USP e seu enquadramento na FAU.

A professora Élide Monzeglio relatou sua participação nas primeiras disciplinas e sobre o formato e a preocupação com que o desenho (visto como instrumental ou artístico) passou a ser ensinado como disciplina de projeto.

Foram histórias que emocionaram a todos os que puderam conhecer as trajetórias do ensino do "desenho" na FAU.

A professora Lucrecia D’Alessio Ferrara nos motivou com uma reflexão sobre o design, relacionando suas características com o desenho e o projeto. Afirmou que "ao projeto cabe a tarefa de fazer, do produto utilitário, uma informação nova $e$, do designer, um agente cultural onde se mostra mais desempenho que competência para que o desenho do produto seja obrigado a antecipar-se ao tempo para marcar o tempo" 2 , concluindo para nossas dúvidas sobre a pesquisa em design, "mas fazer história exige a capacidade de ler o novo e aprender com suas experiências" 3 .

Os depoimentos dos professores João Carlos Cauduro e Ludovico Martino fizeram lembrar as experiências de ensino que vieram a formar a grande parte dos designers atuantes no Brasil. O trabalho destes professores não se limitou ao ensino, foi ampliado pela atuação profissional que impulsionou uma grande participação dos arquitetos nas áreas de desenho do equipamento urbano, desenho institucional, sinalização, identidade corporativa, etc. Foi com muita atenção que todos puderam apreciar e conhecer a imensa contribuição realizada.

Houve também a participação dos professores Issao Minami, Bruno Padovano, Sérgio Régis Martins e Sylvio de Ulhôa Cintra Filho que participaram da mesa de depoimentos sobre o ensino e as experiências do grupo de Programação Visual (PV) da FAU. A mesa foi completada com a presença da professora Élide Monzeglio que revisitou, por meio de diálogo com os participantes, seu depoimento sobre a formação das disciplinas da área da comunicação visual. 
Todos os depoimentos sobre o ensino do design na FAU foram estimulantes. Emocionou a todos o conhecimento dos fatos reveladores do envolvimento da FAU com a construção da cultura material brasileira. Sentimentos que se ampliaram pelo reconhecimento das fendas abertas a serem exploradas no ensino e na pesquisa em design. Emoções que foram partilhadas pelos presentes no reconhecimento de um conjunto de fatos que a história do design no Brasil ainda não conseguiu registrar.

\section{AS MESAS TEMÁTICAS}

O seminário procurou de uma maneira aberta receber a contribuição de pesquisadores e professores da FAU e de outras instituições.

Foram apresentados relatos de pesquisas realizadas ou em realização. Os trabalhos foram distribuídos nos seguintes quatro grandes temas: 1) Design/ Produção e Consumo. 2) Design/Ensino e Pesquisa. 3) Repensando o Design e a Arquitetura. 4) Comunicação Visual/Arte, Programação Visual e Design Gráfico na Arquitetura e na Cidade. Em virtude da presença dos professores João Carlos Cauduro e Ludovico Martino, esta última mesa, que envolveu a participação de outros professores do grupo de disciplinas de PV da FAU, foi tratada como uma sessão de depoimentos.

Notou-se, desde a seleção dos trabalhos, que as linhas divisórias, pretendidas pelas mesas, seriam sempre surpreendidas pelas abordagens dos pesquisadores.

A apresentação das pesquisas demonstrou a diversidade dos temas e objetos contidos sob o rótulo do design. Verificou-se, também, que nos últimos anos ocorreu uma institucionalização acadêmica da produção nesta área - essa produção é devida aos resultados obtidos, às experiências relatadas e suas vinculações com os institutos de pesquisa.

Os temas abordados variaram desde "desenho informal" até análises sobre o eco-design; desde o estudo de materiais até a produção ambiental da cidade; desde análise de elementos da grafia urbana até suas reflexões na configuração do espaço arquitetônico.

Para o melhor entendimento das palestras, depoimentos e apresentações está sendo preparada uma publicação do seminário. Esta publicação tem o objetivo de registrar toda a riqueza das apresentações e permitir seu conhecimento e sua divulgação mais amplos.

Na publicação, também, serão divulgados os artigos dos professores americanos Jacques Giard (Arizona State University) e Lorraine Justice (Georgia Institute of Technology) que devido às dificuldades da aviação internacional, naquele período, não puderam viajar ao Brasil para participarem do seminário. 


\section{CONCLUSÕES}

O objetivo básico do seminário era estabelecer as bases de organização de uma área de "design e arquitetura" no curso de pós-graduação da FAUUSP.

Essa construção, como não poderia deixar de ser, deve emergir de análise de algumas proposições existentes e erigir-se sobre a história das próprias experiências da FAU.

A realização do seminário, portanto, não era um objetivo final, mas um ponto inicial, um momento de acumulação de saberes e estabelecimento de questões.

A presença de 92 (noventa e dois) pesquisadores e professores foi significativa, melhor ainda foi sua atuação, pois agiram de forma participante por meio de questões e debates. Foi observada a presença de profissionais de diversas áreas, tais como: arquitetos, designers, mercadólogos, artistas plásticos, jornalistas, ergonomistas, professores. Este fato indica a diversidade de abordagem dos trabalhos vinculados ao design e à articulação entre as atividades de pesquisa e ensino em design e a prática profissional, em suas múltiplas perspectivas.

A contribuição da FAU para a constituição do design no Brasil foi reconhecida, tanto na história construída como em suas dificuldades atuais para a compreensão das relações entre o design e a arquitetura.

A confrontação com a experiência internacional, em pesquisa sobre design, deve mobilizar nossa atenção para o entendimento de nossa realidade específica dentro do contexto da nova ordem mundial. A contribuição cultural da pesquisa em "design e arquitetura" deve objetivar a construção de uma visão peculiar de nossos problemas na construção ambiente edificado e no conhecimento das relações entre produção e consumo dos artefatos sociais.

Se é possível entrever algumas possibilidades e necessidades da pesquisa em design, cita-se aqui algumas palavras da professora Anna Calvera: "Os pesquisadores que trabalham em países periféricos, qualquer que seja sua distância do centro de produção teórica e científica - que não é um lugar geográfico, mas um grupo de pressão que sanciona o valor das contribuições científicas - têm perante si um trabalho duplo: como o de alcançar os foros internacionais de debate e serem, lá, ouvidos. Trata-se de garantir que os resultados de nossas pesquisas sejam divulgados e que também se Ihes prestem atenção. Este é um trabalho árduo porque deve ser constante, duradouro e custoso. Deveríamos começar, agora, a pensar em caminhos para estabelecer comunicações entre nós. Se o 'desenho' é comunicar e atribuir significado, por que não começamos a usar nossa competência em informar sobre nosso próprio

(4) Trecho da apresentação (texto) da professora Anna Calvera (tradução dos autores). trabalho e seu modo específico de operar?"4

Nos debates e apresentações, mais próximos à FAU, observou-se que o estudo do design na pós-graduação da FAU deverá ter vínculos com a arquitetura e o urbanismo, pois não poderá ser visto como atividade isolada das reflexões sobre o ambiente construído. Como os depoimentos fizeram notar, este 
entendimento sobre o "design e arquitetura" já estava inscrito, desde 1962, nas ocupações da formação do arquiteto na USP.

Enfim, o seminário foi uma pequena oportunidade de rever parte do passado, analisar algumas atividades de pesquisa atuais e estabelecer diretrizes para o estudo, o ensino e a pesquisa do design na USP.

O seminário foi um embrião, um gesto singelo de estabelecer um diálogo que permitiu o entendimento mais adequado sobre nossas linhas de pesquisa e os possíveis direcionamentos para a estruturação do curso de pós-graduação na FAU. O seminário marcou o fim de uma era de isolamento de pesquisadores e docentes brasileiros do design na pós-graduação, e a afirmação da importância da comunidade científica do design entre as comunidades científicas de outras áreas do conhecimento. $\mathrm{O}$ apoio do CNPq e da Pró-Reitoria de Pós-Graduação foi decisivo na realização deste evento.

Participantes

Andréa Franco Pereira - Depoimento

Anna Calvera - Palestra

Anamaria de Moraes - Depoimento

Bruno Padovano - Mesa Temática

Caio Adorno Vassão - Mesa Temática

Carlos Alberto Inácio Alexandre - Coordenador: Mesa Temática

Carlos Alberto Inácio Alexandre - Mesa Temática

Carlos Zibel Costa - Mesa Temática

Cibele Haddad Taralli - Coordenadora: Mesa Temática

Cibele Haddad Taralli - Mesa Temática

Daniela Martins Büchler - Mesa Temática

David Durling - Palestra

Élide Monzeglio - Depoimento

Ermínia T. Menon Maricato - Abertura

Gabriela Gusmão - Mesa Temática

Giorgio Giorgi Junior - Mesa Temática

Guilherme Alexandre Wiedman - Mesa Temática

Guilherme Cunha Lima - Palestra

Guilherme Cunha Lima - Coordenador: Mesa-redonda

Issao Minami - Coordenador: Mesa Temática

Itiro Ida - Mesa-redonda

Jairo Drumond - Mesa-redonda

João Carlos Cauduro - Mesa Temática

José Carlos Plácido da Silva - Depoimento

Júlio Katinsky - Depoimento

Lara Leite Barbosa - Mesa Temática

Lêda Maria Brandão de Oliveira - Mesa Temática 
Luciano Torres Tricárico - Mesa Temática

Lucrécia D'Alessio Ferrara - Depoimento

Ludovico Martino - Mesa Temática

Maria Cecília Loschiavo dos Santos - Palestra

Maria Cecília Loschiavo dos Santos - Mesa Temática

Maristela Mitsuko Ono - Mesa Temática

Mauro Claro - Mesa Temática

Nicolau Guida Neto - Mesa Temática

Rafael Antonio Cunha Perrone - Coordenador: Mesa Temática

Rafael Antonio Cunha Perrone - Mesa Temática

Rita Couto - Mesa-redonda

Sérgio Régis Martins - Mesa Temática

Sylvio de Ulhôa Cintra Filho - Mesa Temática

Virgínia Pereira Cavalcanti - Mesa Temática

Wilson Kindlein - Mesa-redonda 